\title{
Sinorhizobium meliloti RNase III: Catalytic Features and Impact on Symbiosis
}

\author{
Margarida Saramago ${ }^{1}$, Marta Robledo ${ }^{2 \neq \neq}$, Rute G. Matos ${ }^{1 \neq}$, José I. Jiménez-Zurdo ${ }^{2 * \S}$ and \\ Cecília M. Arraiano ${ }^{1 \star \S}$ \\ ${ }^{1}$ Instituto de Tecnología Química e Biológica António Xavier, Universidade Nova de Lisboa, Oeiras, Portugal, ${ }^{2}$ Grupo \\ de Ecología Genética de la Rizosfera, Estación Experimental del Zaidín, Consejo Superior de Investigaciones Científicas, \\ Granada, Spain
}

\section{OPEN ACCESS}

Edited by:

Michael Rossbach,

Vela Diagnostics, Germany

Reviewed by:

Jonathan Perreault,

Institut National de la Recherche

Scientifique (INRS), Canada

Hyouta Himeno,

Hirosaki University, Japan

*Correspondence:

José I. Jiménez-Zurdo

jijz@eez.csic.es

Cecilia M. Arraiano

cecilia@itqb.unl.pt

tPresent address:

Marta Robledo,

Instituto de Biomedicina y

Biotecnología de Cantabria,

Santander, Spain

¥These authors have contributed equally to this work

$\S$ These authors are joint senior authors

Specialty section: This article was submitted to RNA,

a section of the journal

Frontiers in Genetics

Received: 03 May 2018 Accepted: 09 August 2018 Published: 28 August 2018

Citation:

Saramago M, Robledo M, Matos RG, Jiménez-Zurdo Jl and Arraiano CM (2018) Sinorhizobium meliloti RNase III: Catalytic Features and Impact on Symbiosis. Front. Genet. 9:350. doi: $10.3389 /$ fgene.2018.00350
Members of the ribonuclease (RNase) III family of enzymes are metal-dependent double-strand specific endoribonucleases. They are ubiquitously found and eukaryotic RNase III-like enzymes include Dicer and Drosha, involved in RNA processing and RNA interference. In this work, we have addressed the primary characterization of RNase III from the symbiotic nitrogen-fixing $\alpha$-proteobacterium Sinorhizobium meliloti. The S. meliloti rnc gene does encode an RNase III-like protein (SmRNase III), with recognizable catalytic and double-stranded RNA (dsRNA)-binding domains that clusters in a branch with its $\alpha$-proteobacterial counterparts. Purified SmRNase III dimerizes, is active at neutral to alkaline $\mathrm{pH}$ and behaves as a strict metal cofactor-dependent doublestrand endoribonuclease, with catalytic features distinguishable from those of the prototypical member of the family, the Escherichia coli ortholog (EcRNase III). SmRNase III prefers $\mathrm{Mn}^{2+}$ rather than $\mathrm{Mg}^{2+}$ as metal cofactor, cleaves the generic structured R1.1 substrate at a site atypical for RNase III cleavage, and requires higher cofactor concentrations and longer dsRNA substrates than EcRNase III for optimal activity. Furthermore, the ultraconserved E125 amino acid was shown to play a major role in the metal-dependent catalysis of SmRNase III. SmRNase III degrades endogenous RNA substrates of diverse biogenesis with different efficiency, and is involved in the maturation of the 23S rRNA. SmRNase III loss-of-function neither compromises viability nor alters morphology of $S$. meliloti cells, but influences growth, nodulation kinetics, the onset of nitrogen fixation and the overall symbiotic efficiency of this bacterium on the roots of its legume host, alfalfa, which ultimately affects plant growth. Our results support an impact of SmRNase III on nodulation and symbiotic nitrogen fixation in plants.

Keywords: RNA degradation, endoribonucleases, ribonuclease III, Sinorhizobium meliloti, symbiosis

\section{INTRODUCTION}

Ribonucleases (RNases) promote processing and degradation of RNA transcripts to rapidly adjust gene expression according to cellular needs. In the model bacteria Escherichia coli and Bacillus subtilis much is understood about the catalytic features and the role of RNases in RNA turnover (Arraiano et al., 2010). However, in phylogenetically diverse non-classical model microorganisms the sets of RNases are poorly characterized. The $\alpha$-proteobacterium Sinorhizobium meliloti belongs 
to the group of agronomically relevant microorganisms generically referred to as rhizobia, which are well-known for their ability to establish species-specific nitrogen-fixing endosymbioses with legume plants (Fisher and Long, 1992). Only a few studies concerning rhizobial RNases have been reported (Madhugiri and Evguenieva-Hackenberg, 2009; Baumgardt et al., 2014, 2016, 2017; Robledo et al., 2015; Saramago et al., 2017). RNase E is regarded as the major single-strand specific endoribonuclease in gram-negative bacteria (Silva et al., 2011). In S. meliloti, this RNase was shown to be required for small RNA (sRNA)-mediated post-transcriptional silencing of quorumsensing and cell cycle related mRNAs (Baumgardt et al., 2014, 2016; Robledo et al., 2015). On the other hand, in gram-positive bacteria, RNA degradation initiates with RNase Y and RNase J1/2 endoribonucleases (Laalami et al., 2014; Durand et al., 2015). Despite the fact that $S$. meliloti is a gram-negative bacterium, it encodes an RNase J-type enzyme with high similarity to B. subtilis RNase J2. S. meliloti RNase J was suggested to be responsible for the final maturation of the $5^{\prime}$-termini of the two $23 \mathrm{~S}$ rRNA fragments and of $16 \mathrm{~S}$ rRNA (Madhugiri and EvguenievaHackenberg, 2009). Few years ago, the ultraconserved E. coli YbeY protein was characterized as a novel single-strand specific endoribonuclease, whose activity affects ribosome quality control and processing of $16 \mathrm{~S}$ rRNA $3^{\prime}$-terminus (Jacob et al., 2013). Interestingly, it was recently shown that the $S$. meliloti YbeY ortholog exhibits an unprecedented catalytic versatility, being able to cleave both single- and double-stranded RNA substrates (ssRNA and dsRNA). Further, S. meliloti YbeY was shown to promote degradation of $\mathrm{mRNAs}$ from transporter genes upon their antisense interaction with the AbcR2 sRNA (Saramago et al., 2017).

RNase III-like enzymes constitute another group of widely conserved endoribonucleases that have emerged as important players in the post-transcriptional control of gene expression in prokaryotes and eukaryotes. This group of enzymes is also able to cleave RNA molecules internally, within doublestranded segments. In eukaryotes, RNase III-like proteins are involved in RNA interference (RNAi) and RNA maturation (Hammond, 2005). In bacteria, RNase III regulates its own synthesis, is responsible for rRNA operon maturation, processing of cellular and phage RNAs, control of plasmid copy number and maturation of type II CRISPR RNAs (Arraiano et al., 2010; Saramago et al., 2014a, 2015). As a double-strand specific endoribonuclease, this enzyme is a major effector of mRNA processing and decay driven by antisense transcription, and participates in regulation by trans-acting sRNAs (Lasa et al., 2011; Viegas et al., 2011). Intriguingly, RNase III has also been shown to interact in a protective mode with certain dsRNA species (Blaszczyk et al., 2004; Akey and Berger, 2005; Ji, 2006). Activity of this endoribonuclease influences virulence traits of some pathogenic bacteria. Specifically in Salmonella, it is involved in motility, proliferation inside host cells, biofilm development, and antibiotic susceptibility (Viegas et al., 2011, 2013; Saramago et al., 2014b; Matos et al., 2017). Considering the crucial role that RNase III-like proteins play in different organisms, it would be interesting to investigate the function of RNase III in rhizobia. Here, we report on the cofactor-dependent catalytic features of S. meliloti RNase III (SmRNase III) and its impact on the overall symbiotic performance of this rhizobial species on alfalfa (Medicago sativa L.) roots. Our results provide novel insights into RNase III-dependent catalysis and unravel a major role of this enzyme throughout the symbiotic interaction.

\section{MATERIALS AND METHODS}

\section{Sequence Alignment and Phylogenetic Tree Construction}

RNase III sequences from S. meliloti (Uniprot ID: M4MQR5), Rhizobium sp. (Uniprot ID: C3M8S4), Agrobacterium tumefaciens (Uniprot ID: Q8UGK2), Rhodobacter capsulatus (Uniprot ID: Q52698), Pseudomonas aeruginosa (Uniprot ID: Q9XCX9), E. coli (Uniprot ID: P0A7Y0), Salmonella enterica (Uniprot ID: Q56056), Staphylococcus aureus (Uniprot ID: Q2FZ50), B. subtilis (Uniprot ID: P51833), Streptococcus pneumoniae (Uniprot ID: B2IPN5), and Lactococcus lactis (Uniprot ID: Q9CHD0) were aligned using ClustalW21 (Larkin et al., 2007). The phylogenetic tree was built using Phylogeny. fr $^{2}$ (Dereeper et al., 2008, 2010).

\section{Bacterial Strains, Plasmids, and Oligonucleotides}

Bacterial strains and plasmids used in this work along with their sources and relevant characteristics are listed in Supplementary Table S1. S. meliloti strains were routinely grown at $30^{\circ} \mathrm{C}$ in complex tryptone-yeast TY medium (Beringer, 1974). E. coli strains were grown in Luria-Bertani (LB) medium at $37^{\circ} \mathrm{C}$. Antibiotics were added to the media when required at the following concentrations ( $\mu \mathrm{g} / \mathrm{ml}$ ): ampicillin (Ap) 200, kanamycin $(\mathrm{Km}) 50$ for E. coli and 180 for S. meliloti. The sequences of the oligonucleotides used in PCRs or as RNA substrates are provided in Supplementary Table S2.

\section{Overexpression, Purification, and Cross-Linking of Recombinant SmRNase III, E125A, and E125Q Mutants}

The S. meliloti $r n c$ gene (SMc02652) was amplified by PCR from genomic DNA of strain Sm2B3001 with Phusion highfidelity DNA polymerase using the primers RNC_F and RNC_R. The purified 741-bp PCR product was double digested with $\mathrm{NdeI}$ and BamHI and cloned into the histidine tag-containing pET15b vector (Novagen) to yield pET15b-SmRNC. The point mutations E125A and E125Q were introduced into pET15bSmRNC by site-directed mutagenesis using primers E125A_F, E125A_R, E125Q_F, and E125Q_R originating plasmids pET15bSmE125A and pET15b-SmE125Q. All constructs were checked by sequencing (STAB Vida, Portugal).

Plasmids were transformed into E. coli BL21(DE3) recArnc105 strain to allow the expression of the recombinant proteins (Amarasinghe et al., 2001). This derivative strain of BL21(DE3),

\footnotetext{
${ }^{1}$ http://www.ebi.ac.uk/Tools/msa/clustalw2/

${ }^{2}$ http://www.phylogeny.fr
} 
carrying an RNase III mutation, was used because it blocks the autoregulation of SmRNase III by the endogenous E. coli homolog, resulting in a higher yield of the enzyme upon overexpression (Matsunaga et al., 1996).

Cells were grown at $37^{\circ} \mathrm{C}$ to an $\mathrm{OD}_{600}$ of 0.5 in $150 \mathrm{ml} \mathrm{LB}$ medium supplemented with $150 \mu \mathrm{g} / \mathrm{ml}$ ampicillin. At this point, protein expression was induced by addition of $0.5 \mathrm{mM}$ IPTG and bacteria were grown for a further $4 \mathrm{~h}$. Cells were pelleted by centrifugation and stored at $-80^{\circ} \mathrm{C}$. The culture pellet was resuspended in $3 \mathrm{ml}$ of Buffer A $(20 \mathrm{mM}$ Tris- $\mathrm{HCl}, 500 \mathrm{mM}$ $\mathrm{NaCl}, 20 \mathrm{mM}$ imidazole, $\mathrm{pH}$ 8). Cell suspension was lysed using a French Press at 1,000 psi in the presence of $0.1 \mathrm{mM}$ PMSF. The crude extract was treated with Benzonase (Sigma) to degrade the nucleic acids and clarified by a $30 \mathrm{~min}$ centrifugation at $10,000 \times g$. Purification was performed in an ÄKTA FPLC ${ }^{\mathrm{TM}}$ system (GE Healthcare). The cleared lysate was subjected to a histidine affinity chromatography in a HisTrap HP column (GE Healthcare) equilibrated in Buffer A. Proteins were eluted by a continuous imidazole gradient up to $500 \mathrm{mM}$ in Buffer A. The fractions containing the purified protein were pooled together, and subjected to gel filtration using a Superdex 200 Increase 10/300 GL (GE Healthcare) column equilibrated with Buffer B (10 mM Tris- $\mathrm{HCl}, 100 \mathrm{mM} \mathrm{NaCl}$ and $1 \mathrm{mM}$ DTT $\mathrm{pH} 8$ ). The purity of the proteins was verified in a $15 \%$ SDSPAGE gel followed by BlueSafe staining (Nzytech, Portugal). Proteins were quantified using the Bradford method and 50\% $(\mathrm{v} / \mathrm{v})$ glycerol was added to the final fractions prior storage at $-20^{\circ} \mathrm{C}$.

To check whether wild-type $S m$ RNase III and its mutant variants dimerize, $1 \mu \mathrm{g}$ of each of the purified recombinant proteins were incubated in a $10 \mu \mathrm{l}$ cross-linking reaction with $10 \mathrm{mM}$ HEPES pH 7.4, $250 \mathrm{mM} \mathrm{NaCl}, 0.1 \mathrm{mM}$ EDTA, $0.1 \mathrm{mM}$ DTT and increasing concentrations $(2-20 \mu \mathrm{g})$ of DSS (disuccinimidyl suberate). The reaction was performed at room temperature for $30 \mathrm{~min}$ and quenched by adding $1 \mu \mathrm{l}$ of Tris- $\mathrm{HCl}$ $1 \mathrm{M} \mathrm{pH} 7.5$ and SDS loading buffer. Samples were boiled during 5 min and then analyzed in a 15\% SDS-PAGE gel.

\section{In vitro Production of RNA Substrates}

A canonical substrate for RNase III, called R1.1, was generated by in vitro transcription of a synthetic DNA template with a commercial promoter oligonucleotide (StabVida), according to a previously described method (Milligan et al., 1987). Briefly, the synthetic DNA template $(0.5 \mu \mathrm{M})$ and the T7 promoter oligonucleotide $(0.6 \mu \mathrm{M})$ were annealed in $10 \mathrm{mM}$ of Tris- $\mathrm{HCl}$ $\mathrm{pH} 8.0$ by heating for $5 \mathrm{~min}$ at $70^{\circ} \mathrm{C}$, following by incubation for $30 \mathrm{~min}$, at $37^{\circ} \mathrm{C}$. In vitro transcription was carried out using "Riboprobe in vitro Transcription System" (Promega) and T7 RNA polymerase according to the manufacturer's instructions and with a molar excess of $\left[{ }^{32} \mathrm{P}\right]-\alpha$-UTP $(3000 \mathrm{Ci} / \mathrm{mmol} ; 10$ $\mathrm{mCi} / \mathrm{ml}$, which corresponds to $\sim 3 \mu \mathrm{M}$ ) over non-radioactive $\mathrm{UTP}(1 \mu \mathrm{M})$. In order to remove the DNA template, $1 \mathrm{U}$ of DNase (Promega) was added and incubated $30 \mathrm{~min}$ at $37^{\circ} \mathrm{C}$.

The mature form of $\mathrm{tRNA}^{\mathrm{Ser}}$-TGA transcript was also generated. The DNA template for in vitro transcription was PCR amplified from chromosomal DNA of S. meliloti strain 2011. The phage T7 RNA polymerase promoter sequence was included in the $5^{\prime}$ primer sequence. $\mathrm{tRNA}{ }^{\mathrm{Ser}}$ was amplified with the primer pair tRNASerT7FW/tRNASerRev.

All the RNA transcripts produced in vitro were purified by electrophoresis on a $7 \mathrm{M}$ urea/polyacrylamide gel. The gel slice was crushed and the RNA was eluted overnight at room temperature with elution buffer [ $3 \mathrm{M}$ ammonium acetate $\mathrm{pH} 5.2$, $1 \mathrm{mM}$ EDTA, 2.5\% (v/v) phenol pH 4.3]. The RNA was ethanol precipitated, resuspended in RNase-free water and quantified using the BioPhotometer Plus (Eppendorf). The yield of the labeled substrates $(\mathrm{cpm} / \mu \mathrm{l})$ was determined by scintillation counting.

We also used RNA oligoribonucleotides (StabVida) as substrates in some in vitro reactions: 16 and 30 mer alone or both hybridized to the complementary non-labeled 16 mer comp or 30 mer comp to obtain a perfect $16-16$ ds duplex, a doublestranded 30-16 ds substrate with a $3^{\prime}$ poly(A) tail or the perfect 30-30 ds. The hybridization was performed in a 5:1 (mol:mol) ratio by $10 \mathrm{~min}$ of incubation at $80^{\circ} \mathrm{C}$ followed by $45 \mathrm{~min}$ at $37^{\circ} \mathrm{C}$. Efficient duplex formation was checked by binding shift assays in each case. Oligoribonucleotides 16 mer and 30 mer were labeled at their $5^{\prime}$ ends with $\left[\gamma_{-}{ }^{32} \mathrm{ATP}\right]$ and $\mathrm{T} 4$ polynucleotide kinase (Ambion) in a standard reaction.

\section{In vitro Activity Assays}

The activity assays were performed in a final volume of $50 \mu \mathrm{l}$ containing the RNase III activity buffer (30 mM Tris- $\mathrm{HCl} \mathrm{pH} \mathrm{8,}$ $160 \mathrm{mM} \mathrm{NaCl}, 10 \mathrm{mM} \mathrm{MgCl} 2, \mathrm{MnCl}_{2}$, or $\mathrm{CaCl}_{2}$, and $0.1 \mathrm{mM}$ DTT) and the RNA substrate (concentrations indicated in the figure legends). As a control, an aliquot was taken prior to the beginning of each assay and was incubated until the end of the assay (without the enzyme). The reactions were started by the addition of the enzyme and further incubated at the indicated temperature. Aliquots of $5 \mu \mathrm{l}$ were withdrawn at the time-points indicated in the respective figures, and the reactions were stopped by the addition of formamide-containing dye supplemented with $10 \mathrm{mM}$ EDTA. RNase activity assays were carried out at various

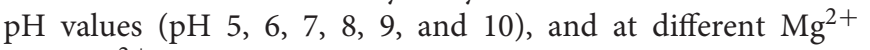
and $\mathrm{Mn}^{2+}$ concentrations $(0.1,1,5,10,50$, and $100 \mathrm{mM})$. Reaction products were resolved in a $7 \mathrm{M}$ urea/polyacrylamide gel. Polyacrylamide concentrations are indicated in the respective figure legends. Signals were visualized by PhosphorImaging and analyzed using ImageQuant software (Molecular Dynamics).

\section{Construction of the S. meliloti rnc Knock-Out Mutant and Phenotypic Tests}

RNase III is encoded in the S. meliloti chromosome as part of the lepB-rnc-era operon. To create an in-frame deletion of the gene, 768-bp SacI/BamHI and 810-bp BamHI/PstI DNA fragments flanking the $r n c$ ORF were PCR amplified from Sm2011 (Casse et al., 1979) genomic DNA with primer pairs 1rncKOSacI_F/2rncKOBamHI_R and 3rncKOBamHI_F/4rncKOPstI_R (Supplementary Table S2), respectively. Reaction products were restricted with the corresponding enzymes, ligated and inserted as a unique fragment between SacI and PstI sites into the suicide vector $\mathrm{pK} 18$ mobsacB to generate plasmid $\mathrm{pKrncKO}$. This plasmid was 
mobilized by biparental matting to S. meliloti Sm2011 using E. coli S17.1 (Simon et al., 1983). Double cross-over events were selected as previously described (Schafer et al., 1994) and the mutants were further checked for the targeted deletion by colony PCR and BamHI restriction of the PCR product. To complement the Sm $\Delta r n c$ mutant, the full-length $r n c$ gene was cloned under the control of the IPTG-inducible $\mathrm{P}_{\text {lac }}$ promoter as follows. The $r n c$ coding sequence was PCR amplified using the pair of primers rncOEI_NdeI_F/BamHI_R. This PCR product was inserted as an $\mathrm{NdeI} / \mathrm{BamHI}$ fragment into the mid-copy plasmid pSRKKm (Khan et al., 2008) to yield pSRKrnc, which was checked by sequencing and conjugated into the $\mathrm{Sm} \Delta r n c$ mutant.

For cell morphology inspection, living wild-type and mutant bacteria were placed on 1\% TY agarose pads and examined under a Nikon Eclipse Ti-E microscope as described (Robledo et al., 2015). To analyze symbiotic phenotypes, alfalfa (M. sativa L. 'Aragón') seeds were sterilized with $\mathrm{HgCl}_{2}$, washed several times and germinated on $1 \%$ agar plates with nitrogen-free mineral solution R\&P (Rigaud and Puppo, 1975) for 24-36 h. One cmlong straight seedlings were transferred to glass tubes containing $20 \mathrm{ml}$ R\&P hydroponic cultures under axenic conditions. After incubation at room temperature in the dark for 3 days, 24 plants were inoculated with $1 \mathrm{ml}$ of $\mathrm{R} \& \mathrm{P}$ suspension containing $10^{6}$ bacteria previously grown in complete TY medium (Beringer, 1974) of the wild-type strain Sm2011, the mutant Sm $\Delta r n c$, or the latter strain harboring either pSRKrnc or the empty vector pSRKKm. Inoculated plants were transferred to a growth chamber programmed for a $16: 8 \mathrm{~h}$ photoperiod. The number of nodules per plant was recorded every 2-3 days, and 30 days after inoculation plants were harvested and shoot length was measured.

\section{RESULTS}

\section{The S. meliloti Genome Encodes an RNase III Ortholog}

The S. meliloti rnc gene (ORF SMc02652 in the genome of the reference strain $\mathrm{Rm} 1021$ ) is predicted to encode an RNase III ortholog, but there are no experimental evidence supporting this prediction. RNase III family members are characterized by conserved structural domains. The bacterial orthologs possess the simplest structures containing an $\mathrm{N}$-terminal catalytic domain (NucD) and a C-terminal dsRNA-binding domain (dsRBD) (Arraiano et al., 2010; Nicholson, 2014). We have aligned the putative S. meliloti 238 amino acid-long RNase III polypeptide ( $S m$ RNase III) with 10 RNase III orthologs from gram-negative ( $\alpha$-proteobacteria and $\gamma$-proteobacteria) and gram-positive microorganisms (Figure 1A). This comparison revealed occurrence in $S m$ RNase III of the well-known conserved residues of RNase III family members, including the signature motif ERLEFLGD within the catalytic domain of the enzyme (Arraiano et al., 2010; Nicholson, 2014). This conservation pattern thus supports a SmRNase III domain arrangement characteristic of these endoribonucleases (Figure 1A). Nonetheless, phylogenetic clustering of these 11 amino acid sequences grouped $S m$ RNase III with its $\alpha$-proteobacterial counterparts, in a branch distinguishable from those of the $\gamma$-proteobacteria and gram-positive bacteria orthologs (Figure 1B).

To further characterize $S m$ RNase III biochemically, we cloned the $r n c$ gene and overexpressed the wild-type protein and two mutant variants in the ultraconserved E125 residue in an E. coli BL21(DE3) recArnc105 strain (see Materials and Methods). RNase III endoribonucleases typically function as homodimers ( $\mathrm{Li}$ and Nicholson, 1996). In order to verify if the recombinant SmRNase III undergoes dimerization, the purified protein was incubated with disuccinimidyl suberate (DSS), which reacts with primary amino groups forming stable amide bonds. Fractionation of the cross-linked protein mixtures in a $12 \%$ SDS-PAGE gel revealed formation of DSS-dependent species that doubled the size of the $S m$ RNase III monomeric form ( $\sim 50 \mathrm{kDa}$ ) (Figure 1C). Substitution of E125 by either alanine (E125A) or glutamine (E125Q) did not compromise SmRNase III dimerization ability.

\section{SmRNase III Is a Metal Cofactor-Dependent Endoribonuclease}

R1.1 is a structured 60 nucleotides (nt)-long RNA molecule containing an asymmetric (4 nt/5 nt) internal loop, and it comes from the phage T7 early region between genes 1.0 and 1.1. This RNA contains an RNase III primary cleavage site (a) that is recognized in vivo and in vitro, and a secondary site (b) that is cleaved only in vitro (Figure 2A) (Dunn and Studier, 1983; Nicholson et al., 1988; Chelladurai et al., 1991, 1993). Therefore, it is commonly used as a model substrate to study RNase III activity in vitro for comparison with previous studies.

RNase III is known to cleave R1.1 at these two preferred sites ( $a$ and $b$ ) in a metal cofactor-dependent manner (Dunn and Studier, 1983; Gross and Dunn, 1987; Li and Nicholson, 1996; Haddad et al., 2013). We first assayed SmRNase III activity on $\mathrm{R} 1.1$ in the presence of $10 \mathrm{mM} \mathrm{Mg}^{2+}, \mathrm{Mn}^{2+}$, or $\mathrm{Ca}^{2+}$ as divalent metal ions (Figure 2A). Both $\mathrm{Mg}^{2+}$ and $\mathrm{Mn}^{2+}$ supported SmRNase III-mediated catalysis of this substrate, whereas $\mathrm{Ca}^{2+}$ did not likely support enzyme activity. Nonetheless, $\mathrm{Mg}^{2+}$ and $\mathrm{Mn}^{2+}$ distinctly influenced SmRNase III cleavage efficiency and $\mathrm{R} 1.1$ breakdown patterns. In $\mathrm{Mg}^{2+}{ }_{\text {-containing buffer, reactions }}$ yielded major R1.1-derived products compatible with cleavage of the substrate at site $a$ (47-nt and 13-nt fragments) similarly to what was observed for RNase III from other microorganisms [data not published and (Sun et al., 2005; Meng and Nicholson, 2008; Haddad et al., 2013)]. Simultaneously, we also observed the presence of other breakdown products (Figure 2A and Supplementary Figure S1). In this condition, large amounts of the full-length R1.1 molecule were still detectable at the end of the assay $(60 \mathrm{~min})$. The same happened when R1.1 was incubated longer $(2 \mathrm{~h})$ and with a higher amount of enzyme (1,200 nM) (Supplementary Figure S2A). Conversely, $\mathrm{Mn}^{2+}$ promoted almost depletion of the substrate and products compatible with an additional cleavage at the canonical $b$ site within R1.1, as it was already reported for other RNase III-like proteins (Meng and Nicholson, 2008; Haddad et al., 2013). The SmRNase III mutant variants E125A and E125Q were largely 


\section{A}

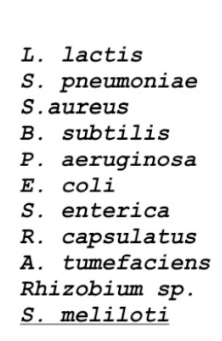

L. lactis

S. pneumoniae

B. subtilis

P. aeruginosa

E. coli

S. enterica

R. capsulatus

A. tumefaciens

Rhizobium sp.

S. meliloti

\section{L. lactis}

S. pneumonia

S. aureus

B. subtilis

$P$. aeruginosa

E. coli

S. enterica

$R$. capsulatus

A. tumefaciens

Rhizobium sp.

S. meliloti

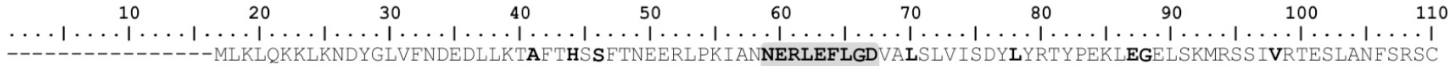
-MKELQTVLKNHFAIEFTDKKLLETAFTHTSYANEHRLIKIS HNERLEFLGDAVLQLLISEYLYKKYPKKPEGDLSKLRAMIVREESLAGEARDC

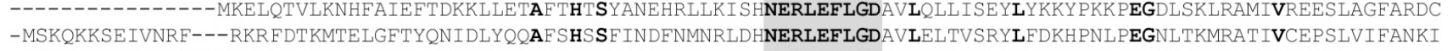
-MSKHSHYKDKKKFYKKVEQEKEFQERISVHFQNEKLLYQAFTHSSYVNEHRKKPYE DNERLEFLGDAVLELTISRFLEAKYPAMSEGDITKLRAAIVCEPSLVSLAHEL

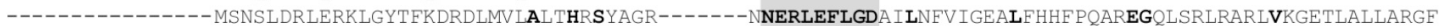

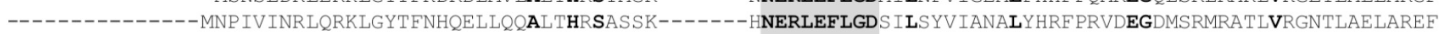

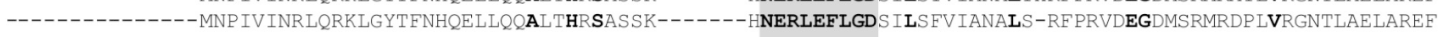
----------MKVAADLSAFMDRLGHRFTTPEHLVRA THSSLGSATR----PDNQRLEFLGDRVLGLSMAEALFHADGRASEGQLAPRENALVRKETCAAVARDI MSK------- TKPLSADEISRLEALIGYEFKEKARLDRALTHASARSAAA----GNYERLEFLGDRVLGLCVAEILESTERNASEGELSVRLNOLVSAESCAAIGDEM MMK--------GRSLSAEDRARLETAIGYQFAEKERLDRALTHSSARNARA----SNYQRLEFLGDRVLGLCVAELLEQTELDANEGEISVRLNQLVSAESCARVADEL -MK------- GRSLNTEDRARLEAAIGYRFAEKERLDRALTHSSARSGRA----INYQRLEFLGDRVLGLCVAEILFQTETDANEGELSVRLNQLVSAESCAKVADEL
\end{abstract}

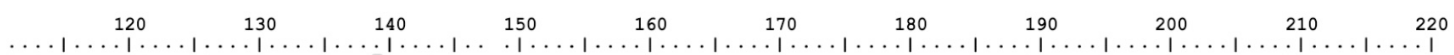

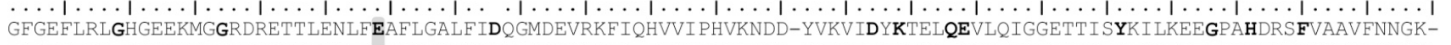
QFDQFIKLGKGEEKSGGRNRDTILGDAFEAFLGALLLDKDVAKVKEFIYQVMI PKVEAGE-FEMITDYKTHLQELLQVNGDVAIRYQVISETGPAHDKVFDVEVLVEGKGLNEMI LIGKGEEKTGGRTRPSLISDAFEAFIGALYLDQGLDIVWKFAEKVIFPHVEQNE-LLGVVDFKTQFQEYVHQQNKGDVTYNLIKEEGPAHHRLFTSEVILQGESFGDLVLIGKGEEMTGGRKRPALLADVFEAFIGALYLDQGLEPVESFLKVYVF PKINDGA-FSHVMD FKSQLQEYVQRDGKGSLEYKISNEKGPAHNREFEA IVSLKGEEVGDYLRL GSGELKSGGERRESI LADAMEALIGAIYLDTGMDSARERI IAWLGPQLRELTPVDTNKD PKTRIQEFLQSRGCDLPRYEVVDIQGEPHCRTFFVDCEVALLS ELGECLRLGPGELKSGGERRESILADTVEALIGGVELDSDIQTVEKLILNWYQTRLDEISPGDKQKDPKTRLQEYLQGRHLPLPTYLVVQVRGEAHDQEFTIHCQVSGLS DLGECLRLGPGELKSGGERRESILADTVEALIGGVELDSNIQTVQ-LILNWYKTRIDEISPGDKQKD PKTRLQEYLQGRHLPLPSYLVVQVRGEAHDQEFTIHCQVSGLS DLGAVLKLGRSEMMSGGRRKDALIGDAMEAVIAAVYLDAGFEVARALVLRLWAARIQSVD--NDARDPKTALQEWAQARGLPPPRYETLGRDGPDHAPQFRIAVVLASGGLHNF IRT GS DVKKLTGKAMLNVRADVVESLIATLYLDGGLEASRKFILKYWQGRATSVD--AGRRDAKTELQEWAHARFAATPAYRVDDRSGP DHDPS FTVTVEIPGVSLHEY IRT GS DVKKITGKHMMNVRADVVES LIAAIYLDGGLEAARRFVLRHWTDRAASAD--GARRDAKTEIQEWAHAKFGAAPRYRTDDRSGP DHDPRF TVTVEVDGISLHEF IRTGSDVKK ITGKHMMNVRADVVESLIAAIYLDGGLDAARRFVLEHWTHRAASAD--GARRDAKTELQEWAHAKFGVAPKYRTDDRSGP DHDPRFTVTVEVDG I$\begin{array}{lll}230 & 240 & \mathrm{~L} \text { E125 } \\ 250 & 250 \cdot 1 \cdot \cdots\end{array}$ $\ldots 1 \ldots 1 \ldots 1 \ldots 1 \ldots 1 \ldots 1 \ldots 1$ ELGRGLGKSKKVAEQKAAENAIK-GQNHVS----SIGQGQGRSKKLAEQEAAKNAVEKGLDSCI----AIAEGKGKTKKESEQRAAESAYKQLKQIK-----PLGVGNGRSKKEAEQHAAQEALAKLQKHHTKQ---
DKTHGHGGSRRIAEQVAAAAALVALGVENGHD--DKTHGHGGSRRIAEQVAAAAALVALGVENGHD---
EPVVGTGSSRRKAEQAAAEQALKKLELE-----EPVVGTGSSRRKAEQAAAN-SVKKLELE------ETEEAQAGSKRNAEQAAAKALLER----IERGA-KPETGVERS KRAAEQVAATRLLEREGVWRKSPTGN APETGTDRSKRGAEQIAAMRLLEREGVWOKRSAGN APETGVDRS KRGAEQVAAMKLEREGVWQKRSAGN
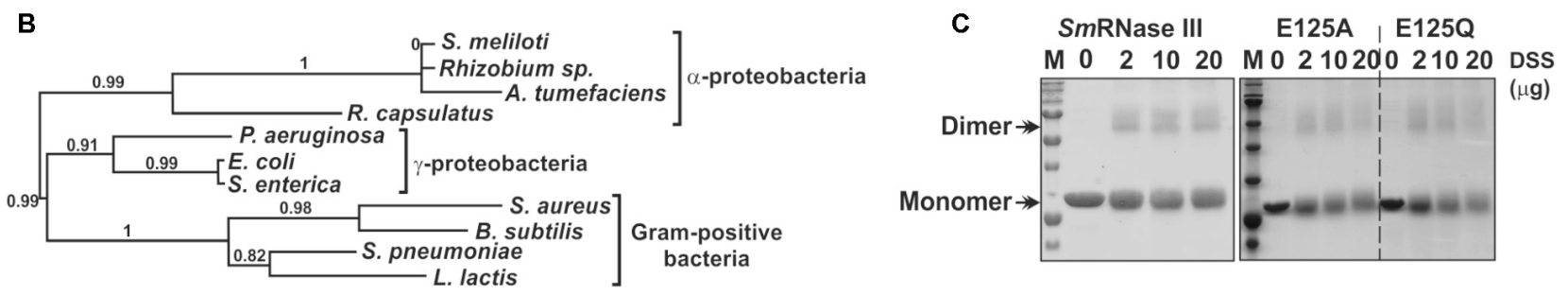

FIGURE 1 | S. meliloti RNase III (SmRNase III) protein features. (A) Sequence alignment of RNase III from Lactococcus lactis (Uniprot ID: Q9CHDO), Streptococcus pneumonia (Uniprot ID: B2IPN5), Staphylococcus aureus (Uniprot ID: Q2FZ50), Bacillus subtilis (Uniprot ID: P51833), Pseudomonas aeruginosa (Uniprot ID: Q9XCX9), Escherichia coli (Uniprot ID: P0A7Y0), Salmonella enterica (Uniprot ID: Q56056), Rhodobacter capsulatus (Uniprot ID: Q52698), Agrobacterium tumefaciens (Uniprot ID: Q8UGK2), Rhizobium sp (Uniprot ID: C3M8S4), and Sinorhizobium meliloti (Uniprot ID: M4MQR5). Fully conserved residues are in bold. The signature sequence of these proteins and the mutated E125 residue are shadowed. The schematic representation of the domain organization of RNase III is also shown, indicating the catalytic domain (NucD) (residues 1-152 in E. coli protein and 1-159 in SmRNase III) and the dsRNA binding domain (residues 153-226 in E. coli protein and 160-238 in SmRNase III). The signature sequence of the catalytic domain is emphasized. (B) Phylogenetic tree of RNase III orthologs from the former species. (C) DSS-mediated cross-linking of wild-type SmRNase III and its mutant variants E125A and E125Q. Approximately $1 \mu \mathrm{g}$ of each purified protein were incubated with increasing concentrations of DSS as indicated on top of the panel. "M" corresponds to the protein standard marker. Proteins were visualized by BlueSafe (Nzytech Portugal) staining.

inactive on R1.1 in the presence of $\mathrm{Mg}^{2+}$, but retained partially cleavage ability at site a of the substrate when $\mathrm{Mn}^{2+}$ was used as cofactor (Figure 2A; right panels). These results indicate that R1.1 cleavage in reactions involving the wild-type enzyme was indeed protein-specific, further suggesting a major role of the ultraconserved E125 amino acid in the metal-dependent catalysis mediated by $S m$ RNase III.
It is known that RNase III-mediated cleavage of R1.1 not only depends on the type of metal cofactor but also on cofactor concentration (Sun and Nicholson, 2001). Therefore, we also tested SmRNase III activity at a wide range of $\mathrm{Mg}^{2+}$ and $\mathrm{Mn}^{2+}$ concentrations (0.1-100 mM) (Figure 2B). Increased $\mathrm{Mg}^{2+}$ concentrations favored enzyme activity without altering R1.1 cleavage patterns, with almost total consumption of the 


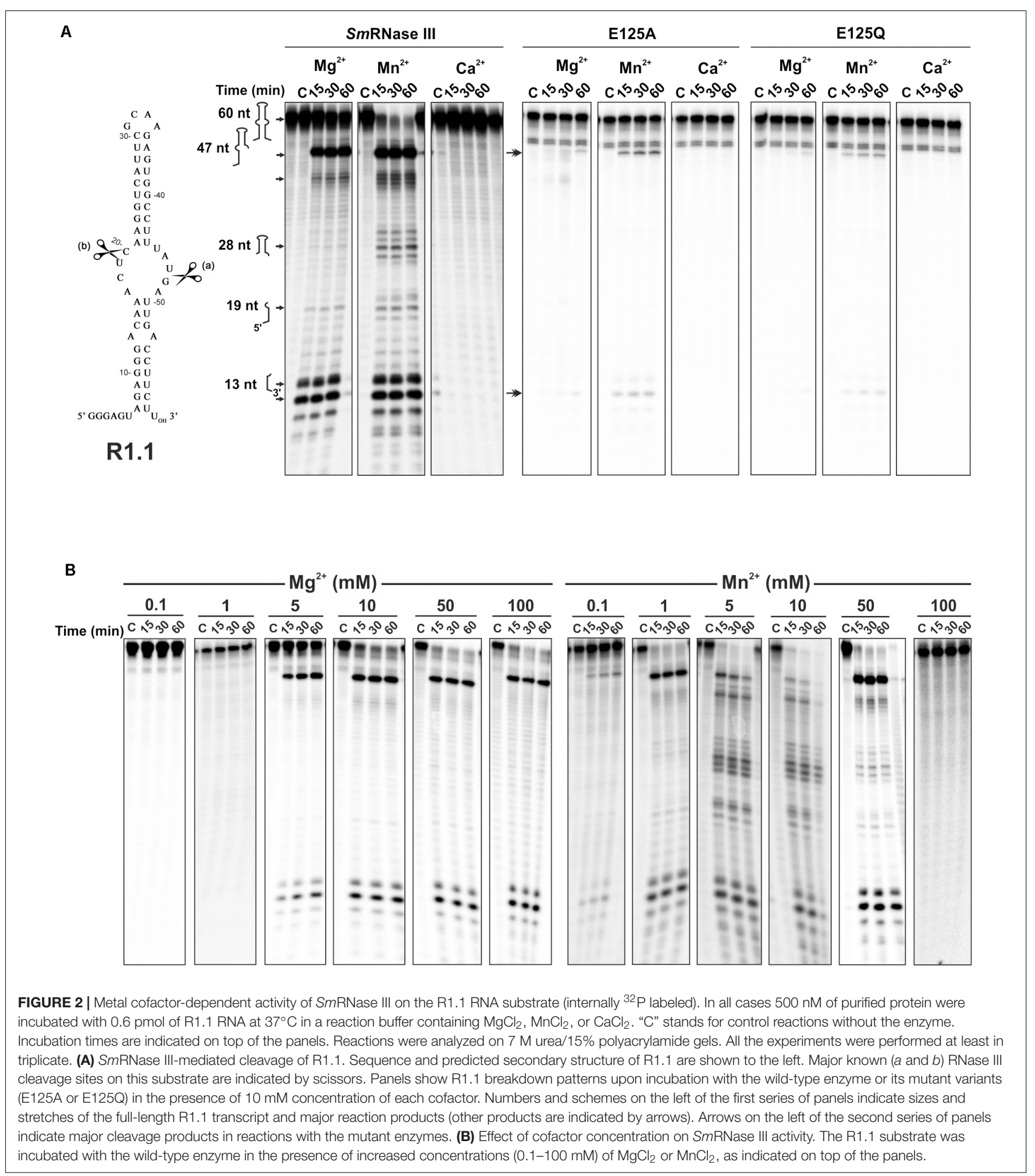

substrate at 50 and $100 \mathrm{mM}$. In contrast, SmRNase III displayed similar efficiency for R1.1 degradation in the window of 1-50 $\mathrm{mM} \mathrm{Mn}^{2+}$ concentration, whereas higher concentrations of this cofactor $(100 \mathrm{mM})$ rendered the enzyme inactive (Figure 2B and Supplementary Figure S1). Collectively, these findings confirmed the strictly metal cofactor-dependent activity of SmRNase III on the model R1.1 substrate.

Another variable that may affect RNase III-mediated catalysis is $\mathrm{pH}$. In a new series of in vitro experiments, we assayed SmRNase III for R1.1 cleavage at $\mathrm{pH}$ values ranging from 5.0 to 

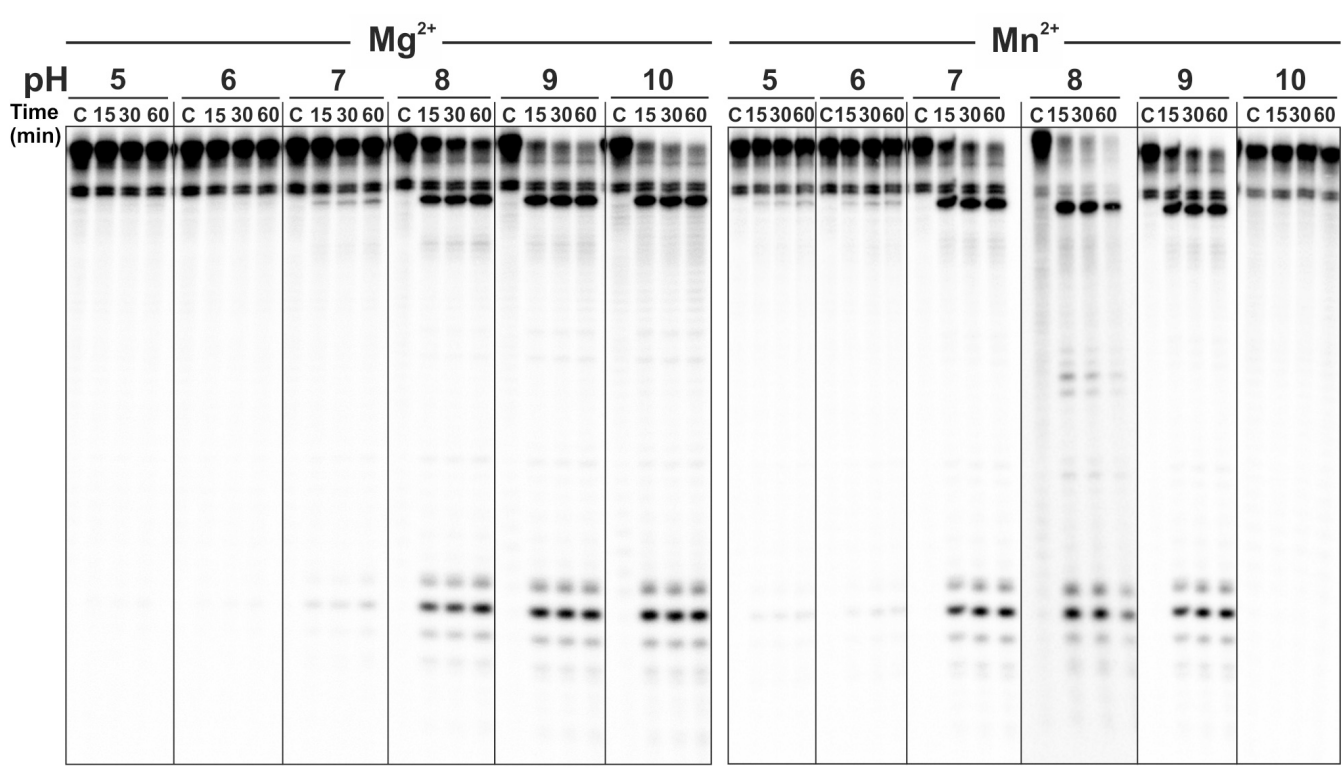

FIGURE 3 | Effect of pH on SmRNase III activity. The wild-type enzyme (500 nM) was incubated with the R1.1 RNA substrate internally ${ }^{32} \mathrm{P}$ labeled (0.6 pmol) at $37^{\circ} \mathrm{C}$ in the presence of $10 \mathrm{mM} \mathrm{MgCl}_{2}$ or $\mathrm{MnCl}_{2}$ buffered at $\mathrm{pH}$ values ranging from 5 to 10 as indicated on top of the panels. "C" corresponds to control reactions without the enzyme. Incubation times are indicated on top of the panels. Reactions were analyzed on $7 \mathrm{M}$ urea/15\% polyacrylamide gels. This experiment was performed at least in triplicate.

10, in the presence of $10 \mathrm{mM} \mathrm{Mg}^{2+}$ and $\mathrm{Mn}^{2+}$ (Figure 3). $\mathrm{Mg}^{2+}$ supported maximal enzyme activity at the highest $\mathrm{pH}$ values tested ( $\mathrm{pH} 8.0-10)$, whereas the use of $\mathrm{Mn}^{2+}$ as a cofactor shifted optimal activity to neutral or moderate alkaline conditions $(\mathrm{pH}$ 7-9). These data indicate that tolerance of SmRNase III to $\mathrm{pH}$ oscillations is also conferred by the metal cofactor.

\section{SmRNase III Is Double-Strand Specific and Exhibits Different Preference for Endogenous RNA Substrates}

The well-characterized $E c$ RNase III requires a minimal substrate length of $\sim 11$ bps for an efficient, but mostly unspecific cleavage (Nicholson, 2014). To test if SmRNase III behaves similarly with respect to this parameter, we evaluated the ability of the enzyme to degrade a small 16-bp fully dsRNA molecule (16-16 dsRNA) a partially dsRNA with a poly(A) tail (30-16 ds), and a longer 30bp dsRNA substrate (30-30 ds) in the presence of $10 \mathrm{mM} \mathrm{Mg} \mathrm{Mg}^{2+}$ (Figure 4A). SmRNase III did not react with either the 16-16 ds (data not shown) or the 30-16 ds substrates, whereas the 30$30 \mathrm{ds}$ molecule was fully degraded, with concomitant appearance of likely specific breakdown products (Figure 4A). The enzyme neither reacted with the single-stranded versions of these RNAs (i.e., 16 mer and 30 mer oligonucleotides) (Supplementary Figure S2). These results confirmed that $S m$ RNase III is a typical double-strand specific endoribonuclease, but with a minimal substrate length requirement different from that of its enterobacterial ortholog.

Bacterial RNase III is known to process or degrade diverse RNA species within the cell, including mRNAs, tRNAs, and rRNAs. Therefore, we also tested SmRNase III activity on a number of in vitro transcribed $S$. meliloti native RNA species, i.e., $r n c$ and $y b e Y$ mRNAs and mature tRNA ${ }^{\text {Ser }}$ (Figure $4 \mathbf{B}$ ). In the presence of $\mathrm{Mg}^{2+}$ as cofactor, the enzyme was very efficient for cleaving its coding mRNA $(r n c)$ with rapid consumption of the total substrate. Similarly, SmRNase III degraded the mRNA encoding the endoribonuclease YbeY in the same incubation conditions, but this reaction yielded discrete breakdown products. In contrast, the activity on the mature tRNA $^{\text {Ser }}$ transcript was extremely weak. Finally, we compared the rRNA profiles of the wild-type strain and its derivative lacking the endoribonucleases SmRNase III (Sm $\Delta r n c)$ (Figure 4C). Accumulation of misprocessed 23S rRNA species (30S rRNA) was evident in mutant bacteria lacking specifically SmRNase III, suggesting that the precursor transcript of the largest rRNA is also a native substrate of this enzyme. Altogether, these findings anticipate a differential contribution of SmRNase III to the turnover and processing of native $S$. meliloti RNA transcripts of diverse biogenesis.

\section{SmRNase III Influences Free-Living Growth and Symbiotic Performance of} S. meliloti on Alfalfa Roots

To further address the biological role of SmRNase III genetically, we characterized the morphology, growth, and symbiotic phenotypes of the $r n c$ knock-out mutant, Sm $\Delta r n c$. Lack of $S m$ RNase III did not alter wild-type length and shape of S. meliloti cells, suggesting that this endoribonuclease is not a major determinant of cell division and morphogenesis in this bacterium (data not shown). However, the mutant displayed a markedly delayed growth in complete TY medium with respect to the 
A

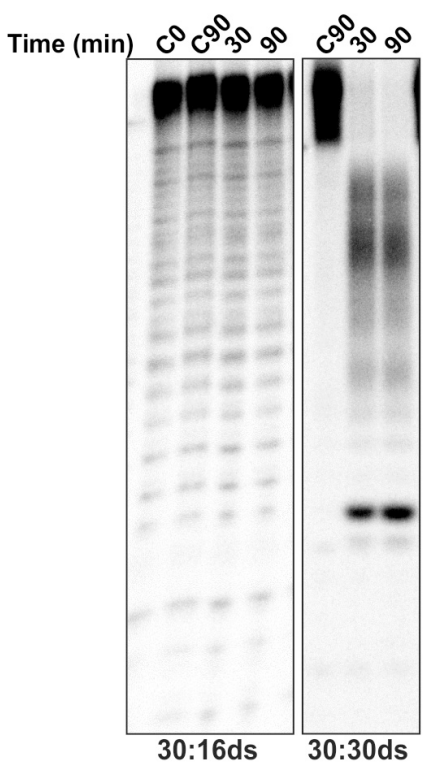

30:16ds

5 ' - CCCGACACCAACCACUAAAAAAAAAAAAAA- 3 '

$3^{\prime}$ - GGGCUGUGGUUGGUGA-5'

30:30ds

5 ' - CCCGACACCAACCACUAAAAAAAAAAAAAA-3 '

3 ' -GGGCUGUGGUUGGUGAUUUUUUUUUUUUUUUU-5 '
B
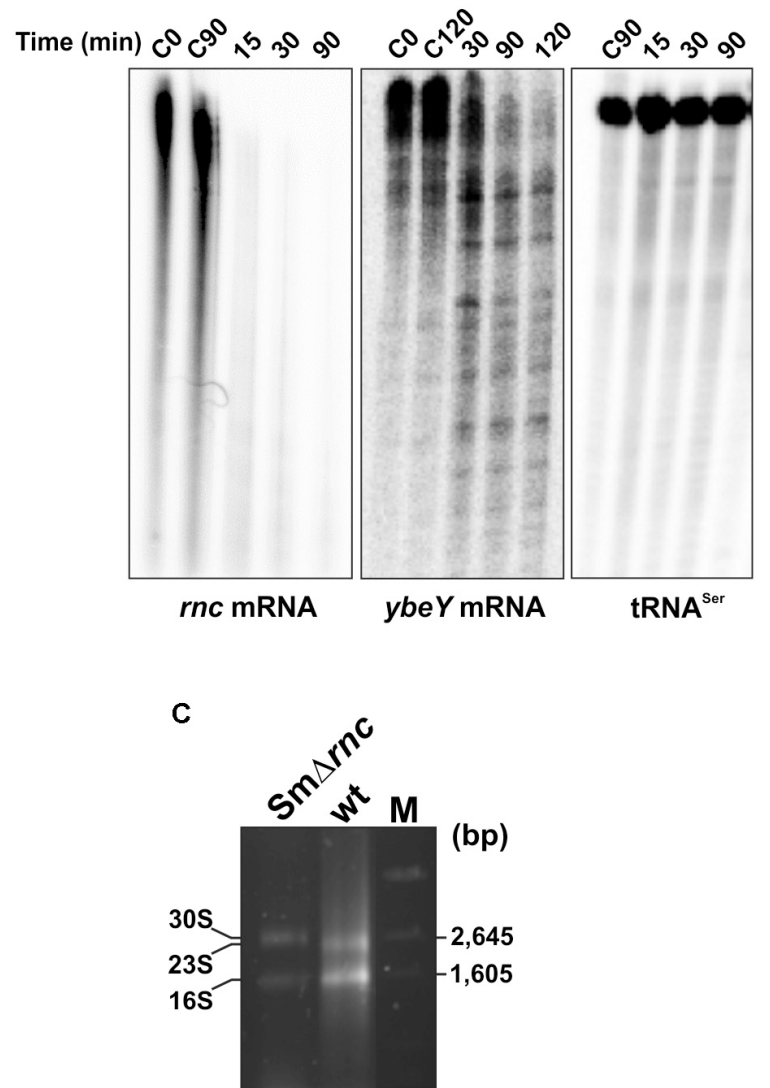

FIGURE 4 | SmRNase III activity on other generic and endogenous RNA substrates. In vitro reactions were performed at $37^{\circ} \mathrm{C}$ at the time-points indicated on top of the panels. "C" corresponds to control reactions without the enzyme. Experiments were performed at least in triplicate. (A) Activity on generic dsRNA substrates. The wild-type enzyme (500 mM) was incubated with 0.1 pmol of 16-16ds, 30-16ds or 30-30 ds (5 'end-labeled) in the presence of 10 mM MgCl 2 . Sequence of each substrate is indicated on bottom of the panels. Reactions were analyzed on $7 \mathrm{M}$ urea/20\% polyacrylamide gels. (B) Activity on endogenous S. meliloti substrates. SmRNase III (500 nM) was incubated with in vitro synthetized rnc mRNA (0.12 pmol), ybeY mRNA (0.15 pmol), or tRNA ${ }^{\text {Ser }}(0.10$ pmol) in the presence of $10 \mathrm{mM} \mathrm{MgCl}_{2}$. Reactions were analyzed on $7 \mathrm{M}$ urea/5\% (tRNA ${ }^{\text {Ser }}$ ), $8 \%$ (ybeY), or $10 \%$ (rnc) polyacrylamide gels. (C) Influence of SmRNase III on rRNA maturation. rRNA profiles of the S. meliloti wild-type Rm2011 strain and its mutant derivative Sm $\Delta r n c$ analyzed by $0.7 \%$ Synergel/0.9\% agarose electrophoresis. Sizes of the mature $23 \mathrm{~S}$ and $16 \mathrm{~S}$ rRNA species are indicated. 30 S denotes the misprocessed 23S rRNA. M, DNA molecular weight marker.

parent strain, reaching the stationary phase at a lower optical density (Figure 5). Growth rate of the mutant was restored to wild-type levels with plasmid pSRKrnc, which expresses the SmRNase III coding gene from an IPTG-inducible $\mathrm{P}_{\text {lac }}$ promoter. Of note, this growth phenotype was complemented even in the absence of the inducer, which indicates that a low intracellular accumulation of SmRNase III resulting from uninduced background transcription is enough to fulfill its physiological function.

We next investigated the overall impact of SmRNase III in S. meliloti symbiotic performance (Figure 6). For that, series of 24 alfalfa plants grown hydroponically in test tubes were independently inoculated with the wild-type bacteria, the mutant Sm $\Delta r n c$, the strain complemented with plasmid pSRKrnc, and a control Sm $\Delta r n c$ derivative carrying the empty vector pSRK. The number of nodules appearing in each plant was recorded at daily intervals to determine nodulation kinetics (\% of nodulated plants; Figure 6A) and nodulation efficiency
( $\mathrm{n}^{\circ}$ nodules per plant; Figure 6B) of each strain. This symbiotic test evidenced a marked delay of the Sm $\Delta r n c$ mutant with respect to its parent strain for plant nodulation. At the end of the assay [22 days post inoculation (dpi) of the plants], bacteria lacking SmRNase III hardly nodulated $70 \%$ of the inoculated plants, whereas all the plants treated with the wildtype strain developed nodules. Similarly, the average number of nodules induced by the wild-type strain per plant was more than 2-fold than that recorded in $S m \Delta r n c$-inoculated plants.

A detailed observation of nodules emerging in roots of wild-type and mutant-inoculated alfalfa plants revealed also a great delay in the appearance of nitrogen-fixing nodules, easily identifiable as pink colored structures because of leghemoglobin expression (Figure 6C). At the end of the symbiotic test, more than $90 \%$ of plants treated with wild-type bacteria were scored as nitrogen-fixing (i.e., developed at least one pink nodule), whereas this parameter was scarcely $30 \%$ in the assay involving 

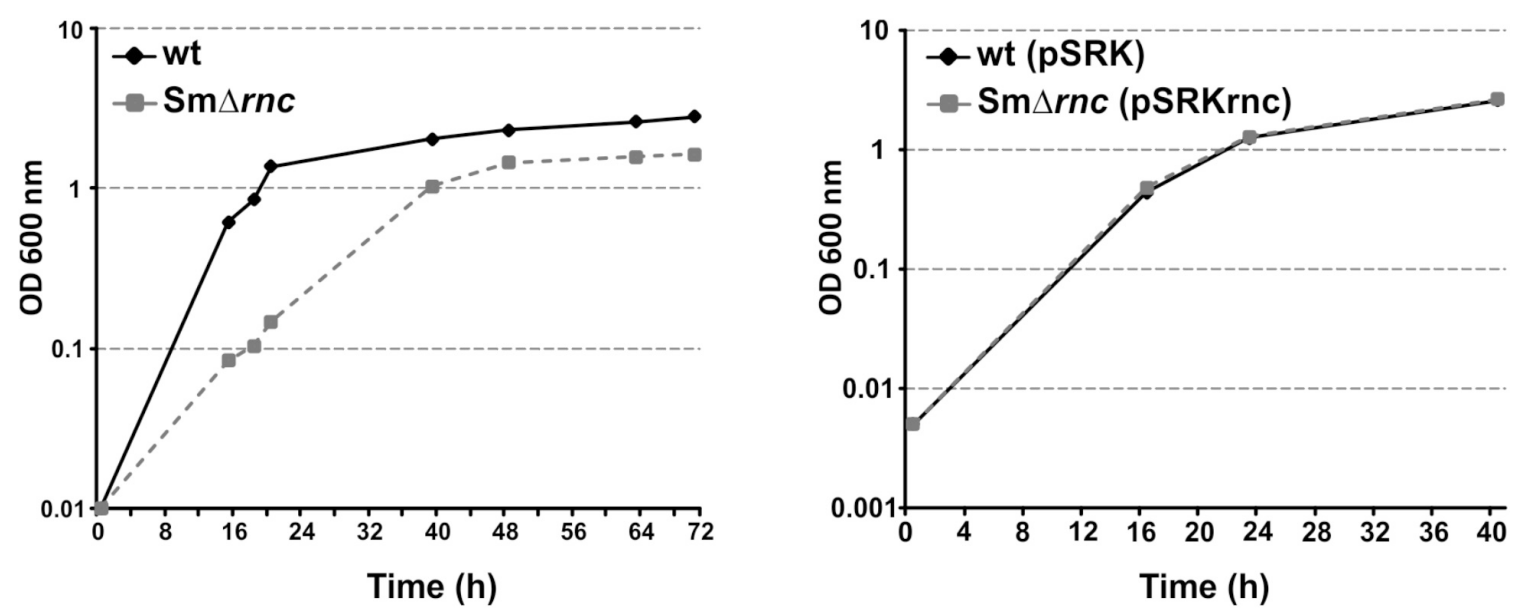

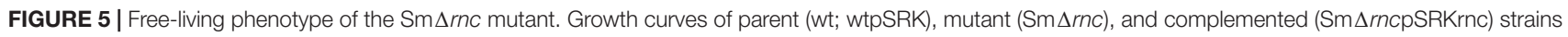
as determined by $\mathrm{OD}_{600}$ readings of TY cultures. Growth of wild-type bacteria harboring the empty vector pSRK was used as the control reference for the complemented strain.

the mutant strain. All these symbiotic phenotypes were partially complemented with plasmid pSRKrnc.

The delayed kinetics of appearance of pink nodules suggests that lack of $S m$ RNase III compromises symbiotic nitrogen fixation, which may ultimately affect plant growth. To test this, we collected the alfalfa plants and measured their shoot length (Figure 6D). Plants inoculated with the wild-type and complemented strains developed significantly longer shoots than those inoculated with the mutant bacteria, $S m \Delta r n c$ or $S m \Delta r n c$ (pSRK), which were similar to those of the control mocktreated plants. Together, these findings suggest that $S m$ RNase III profoundly influences nodulation and the onset of symbiotic nitrogen-fixation in S. meliloti.

\section{DISCUSSION}

Ribonucleases are key elements of post-transcriptional regulatory networks that remain poorly characterized in the vast majority of bacterial species. The widespread RNase III family of enzymes are metal cofactor-dependent double-strand specific endoribonucleases, which fulfill prominent roles in bulk mRNA turnover, rRNA/tRNA processing and regulation of gene expression by trans-acting and antisense sRNAs. Here, we report the first biochemical characterization of the RNase III ortholog from S. meliloti and provide genetic evidence of a major requirement of this enzyme for the establishment of an efficient nitrogen-fixing endosymbiosis between this bacterium and its host legume, alfalfa.

The putative protein product of the $S$. meliloti $r n c$ gene exhibits features common to all RNase III family members, i.e., recognizable catalytic and dsRNA-binding motifs, dimerization potential and strict metal cofactor-dependent catalysis of the generic R1.1 model RNA substrate. Nonetheless, our in vitro assays uncovered important differences between SmRNase III and its well-characterized enterobacterial ortholog (EcRNase
III) regarding divalent metal ion requirements for optimal catalysis and site-specific R1.1 cleavage. It is known that both $\mathrm{Mg}^{2+}$ and $\mathrm{Mn}^{2+}$ similarly support efficient EcRNase IIImediated R1.1 cleavage, if provided in the reactions at optimal concentrations, whereas $\mathrm{Ca}^{2+}$ does not support catalysis (Sun and Nicholson, 2001). EcRNase III attains optimal activity in the presence of relatively low concentrations of $\mathrm{Mg}^{2+}(\sim 2 \mathrm{mM})$ and $\mathrm{Mn}^{2+}(0.1-1 \mathrm{mM})$, but higher $\mathrm{Mn}^{2+}$ concentrations ( $>5 \mathrm{mM}$ ) have an inhibitory effect on R1.1 cleavage (Sun and Nicholson, 2001). In contrast, our data showed that SmRNase III demands significantly higher concentrations of both $\mathrm{Mg}^{2+}(10 \mathrm{mM})$ and $\mathrm{Mn}^{2+}$ (1-50 mM) for R1.1 depletion. As for EcRNase III, increased $\mathrm{Mn}^{2+}$ concentrations and the presence of $\mathrm{Ca}^{2+}$ blocked the activity of the enzyme. It has been hypothesized that $\mathrm{Ca}^{2+}$ does not support EcRNase III catalysis due to its larger radius and different ligand coordination properties (Nicholson, 2014). Unlike EcRNase III, our data indicate that the $S$. meliloti ortholog prefers $\mathrm{Mn}^{2+}$ rather than $\mathrm{Mg}^{2+}$ as cofactor, which has been already reported for other members of the RNase III family of enzymes (Haddad et al., 2013; Wu et al., 2016). The nature of the metal cofactor seems to be also a major determinant of SmRNase III tolerance to other external variables such as $\mathrm{pH}$. Changes in intracellular $\mathrm{pH}$ values are known to affect many biological processes, such as enzymes activity. Thus, we can speculate that modulation of SmRNase III activity at different $\mathrm{pH}$ values by metal cofactors, may help bacteria to cope with alkaline stress, namely in the presence of $\mathrm{Mg}^{2+}$.

RNase III enzymes have highly conserved residues in the catalytic domain that were suggested to have an important role in activity (Blaszczyk et al., 2004; Akey and Berger, 2005; Ji, 2006; Davies and Walker, 2007). Based on crystallographic data, a twometal ion catalytic mechanism has been proposed for RNase III. This model suggests that both metals are equally coordinated by four of these residues in the E. coli enzyme, i.e., E41 and D45 that belong to the signature box (NERLEFLGDS), and D114 


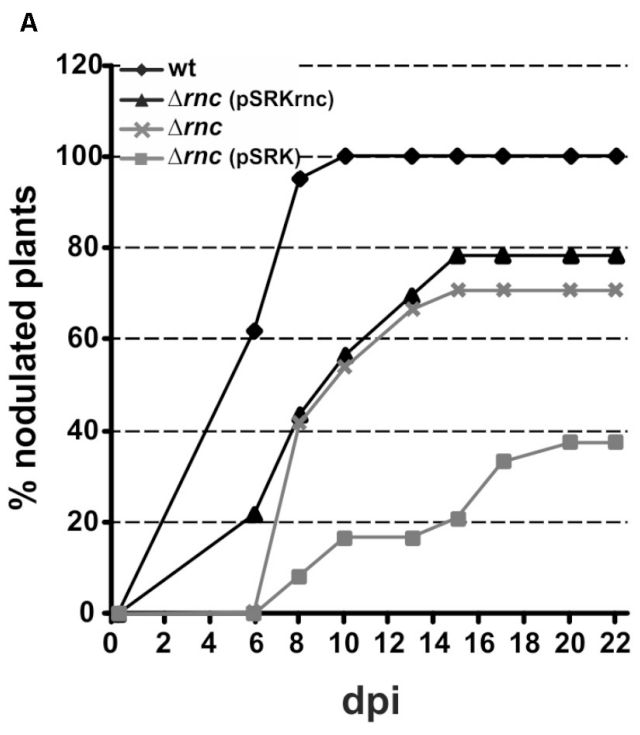

C

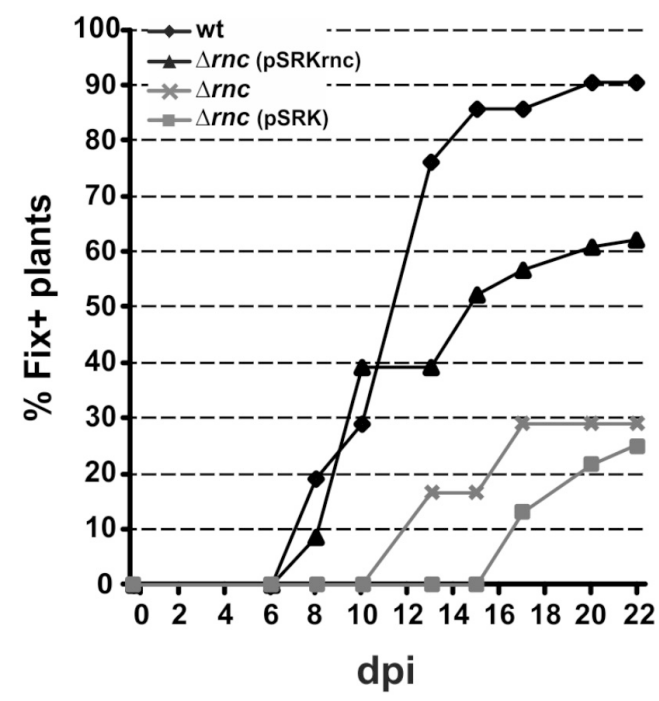

B

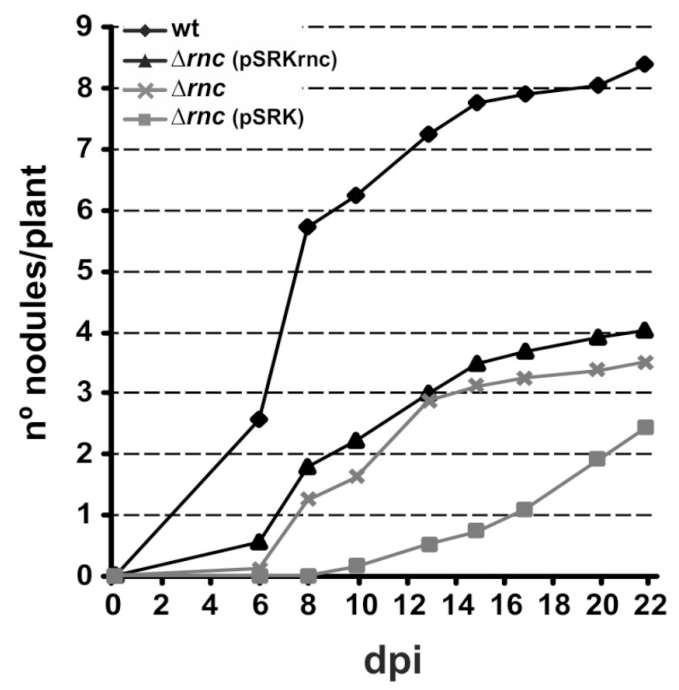

D

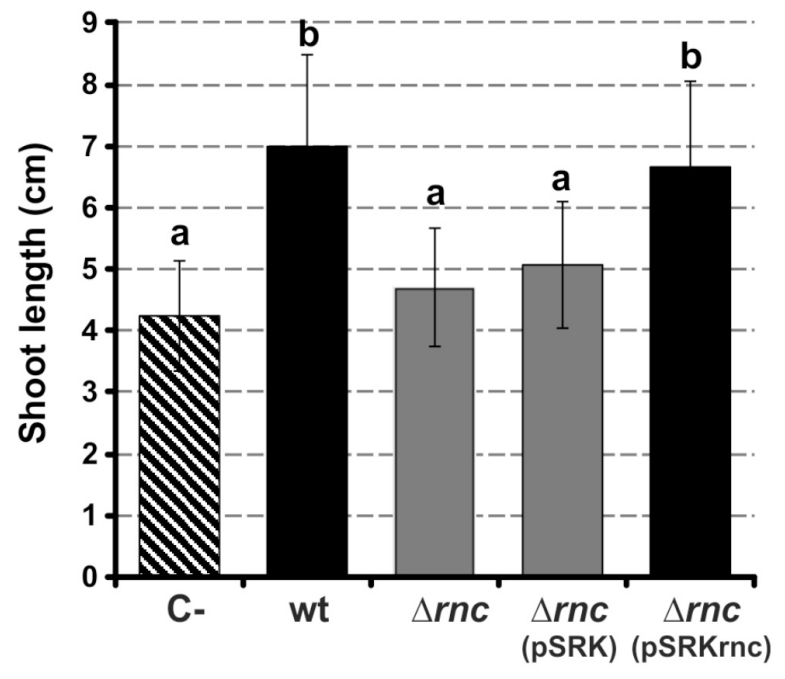

FIGURE 6 | Symbiotic phenotype of the Sm $\Delta r n c$ mutant. Alfalfa plants were inoculated with wild-type (wt), RNase III mutant ( $\Delta r n c)$, complemented ( $\Delta r n c p S R K r n c)$, or control ( $\Delta$ rncpSRK) strains. The \% nodulated plants (A), $n^{\circ}$ nodules/plant (B) and \%Fix ${ }^{+}$plants (i.e., developing at least one pink nodule) (C) were recorded at daily intervals and plotted. Shown is a representative example of two independent experiments. Dpi, days post-inoculation. (D) Shoot-length of the plants at the end of the assay. Plotted are mean and standard deviation of measurements in a total of 48 plants in two independent experiments. Statistical significance at $P<0.05$ is indicated by letters. C-, uninoculated plants.

and E117, all within the catalytic motif of the enzyme (Blaszczyk et al., 2004; Sun et al., 2005). The substitution of E117 by either alanine (E117A) or glutamine (E117Q) residues induces minimal structural changes but abolishes the endonucleolytic activity of $E c$ RNase III in the presence of $\mathrm{Mg}^{2+}$ without compromising binding to dsRNA (Li and Nicholson, 1996; Dasgupta et al., 1998; Amarasinghe et al., 2001; Haddad et al., 2013). Identical substitutions of the equivalent E117 residue in the $S$. meliloti protein (E125A and E125Q) similarly blocked enzyme activity but supported cleavage at position " $a$ " within R1.1 (Figure 2) with $\mathrm{Mn}^{2+}$ as cofactor. Therefore, it is likely both amino acid substitutions render an environment no longer suitable for $\mathrm{Mg}^{2+}$ binding. Crystallographic reports have suggested that $\mathrm{Mg}^{2+}$ and $\mathrm{Mn}^{2+}$ binding sites have identical coordination in RNase III (Blaszczyk et al., 2001). However, our observations further support the theory of the existence of a third binding site on the enzyme specific for $\mathrm{Mn}^{2+}$ (Sun et al., 2005). This interpretation explains the inhibition of $S m$ RNase III activity as $\mathrm{Mn}^{2+}$ concentrations increased, whereas $\mathrm{Mg}^{2+}$, which is not expected to recognize such $\mathrm{Mn}^{2+}$ inhibitory site, is not a limiting factor for catalysis (Sun et al., 2005).

In addition to the primary cleavage site " $a$ " within R1.1, which is recognized by RNase III in vivo and in vitro, it is known that this enzyme cleaves this substrate at a secondary 
site " $b$ " under specific conditions (Gross and Dunn, 1987) (Figure 2). Interestingly, we also noticed that SmRNase III is able to cleave R1.1 other sites at regardless the cofactor used, whereas $\mathrm{Mn}^{2+}$ specifically promotes cleavage at position " $b$ ". These findings anticipate that $S$. meliloti and enterobacterial RNase III orthologs likely recognize different sequence motifs within the RNA substrates. This possibility is further supported by the observation that $S m$ RNase III activity demands longer dsRNA substrates than its enterobacterial counterpart. The S. meliloti genome encodes another endoribonuclease called YbeY that exhibits RNase III-like metal cofactor-dependent catalytic features for cleaving structured and dsRNA substrates (Saramago et al., 2017). However, SmYbeY also degrades ssRNA whereas $S m$ RNase III is double-strand specific, which predicts a different contribution of both enzymes to RNA processing and turnover in S. meliloti.

$E c$ RNase III is able to regulate its synthesis by a feedback loop that involves cleavage of its own message (Matsunaga et al., 1996). Two lines of experimental evidence support autoregulation of $S m$ RNase III in a similar manner: higher yields of the recombinant protein when it is expressed in a genetic background lacking a functional RNase III (e.g., E. coli BL21(DE3) recArnc105), and efficient cleavage of its coding mRNA in vitro. It is also known that RNase III participates in the maturation of rRNAs (Arraiano et al., 2010). Lack of this enzyme resulted in the accumulation of misprocessed $23 \mathrm{~S}$ rRNA species (probably 30S rRNA), indicating that SmRNase III is specifically involved in maturation of this housekeeping RNA. RNase III-dependent processing of $23 \mathrm{~S}$ rRNA has been reported in a number of $\alpha$-proteobacteria including the $S$. melilot $i$ close relative, Sinorhizobium fredii. It likely relies on RNase III-mediated cleavage within intervening sequences occurring specifically in the helix 9 of the $\alpha$-proteobacterial 23S rRNA precursors (Evguenieva-Hackenberg and Klug, 2000).

The fundamental function of RNases typically influences widely diverse cellular processes. In line with this notion, we have shown that lack of SmRNase III conferred growth and symbiotic defects to $S$. meliloti. Nonetheless, core control of cell division and morphogenesis does not seem to underlie this apparent pleiotropic phenotype, suggesting that $S m$ RNase III participates in specific $S$. meliloti free-living and symbiotic post-transcriptional regulatory networks. Our in vitro data are consistent with a proficient activity of $S m$ RNase III under several external conditions, which are known to be relevant for S. meliloti lifestyle. Maintenance of metal and $\mathrm{pH}$ homeostasis is essential for proper functioning of cells, and has significant implications for microbial adaptations to changing environments. During transition from a free-living state in soil to the intracellular residence within the nodules that $S$. meliloti induce in the roots of its host plant, the essential nutrients $\mathrm{Mg}^{2+}, \mathrm{Mn}^{2+}$, and $\mathrm{Ca}^{2+}$ are differentially available and $\mathrm{pH}$ fluctuates. The optimum $\mathrm{pH}$ for rhizobial growth is neutral or slightly alkaline. Accordingly, acidity severely compromises $S$. meliloti survival in soil, nodule development and symbiotic nitrogen fixation (Ferguson et al., 2013). During early root hair infection, S. meliloti is exposed to the reactive oxygen species (ROS) released by the plant host as a defense response (Soto et al., 2009). Manganese has been shown to be important to counteract ROS effects, whereas $\mathrm{Mg}^{2+}$ transport is essential for microaerobic nitrogen-fixation in late symbiotic stages (Davies and Walker, 2007; Hood et al., 2015; Hood et al., 2017). It is therefore tempting to speculate on a key role of divalent metal ions in the control of SmRNase III activity in vivo. The symbiotic phenotype of bacteria lacking SmRNase III anticipates the involvement of this enzyme in RNA processing and turnover during all steps of the symbiotic interaction. As double-strand specific endoribonuclease, RNase III is expected to mediate gene silencing triggered by sRNAs. The non-coding transcriptome of $S$. meliloti has been characterized in recent years, and a particular bias of antisense transcription to genuine symbiotic genes has been reported (Robledo et al., 2015). Our work, thus provide a base-line for the forthcoming investigation of the discrete participation of SmRNase III in post-transcriptional symbiotic regulatory networks.

\section{AUTHOR CONTRIBUTIONS}

MS, MR, RGM, JJ-Z, and CMA conceived and designed the experiments, and interpreted the data. JJ-Z and CMA supervised the work. MS, MR, and RGM performed the experiments. MS and JJ-Z wrote the paper. MR, RGM, and CMA critically read the manuscript.

\section{FUNDING}

This work was funded by project LISBOA-01-0145-FEDER007660 (Microbiologia Molecular, Estrutural e Celular) funded by FEDER funds through COMPETE2020 - Programa Operacional Competitividade e Internacionalização (POCI) and by FCT Fundação para a Ciência e a Tecnologia to CMA; project PTDC/BIA-MIC/1399/2014. In addition, FCT provides postdoctoral grants ref SFRH/BPD/109464/2015 to MS and ref SFRH/BPD/75887/2011 to RGM. This work was also funded by the ERDF-cofinanced grants BFU2013-48282-C2-2-P and BFU2017-82645-P from the Spanish Ministerio de Economía, Industria $\mathrm{y}$ Competitividad (MINEICO) to JJ-Z; MR was supported by a contract of the Programa de Formación PostDoctoral Juan de la Cierva from MINEICO.

\section{ACKNOWLEDGMENTS}

We are grateful to Prof. A. Nicholson for kindly providing us with the E. coli BL21(DE3) recArnc105 strain. We thank Ascensión Martos and Teresa Baptista da Silva for technical assistance. We also thank the core facilities of EEZ-CSIC for routine sequencing of plasmid constructs.

\section{SUPPLEMENTARY MATERIAL}

The Supplementary Material for this article can be found online at: https://www.frontiersin.org/articles/10.3389/fgene.2018. 00350/full\#supplementary-material 


\section{REFERENCES}

Akey, D. L., and Berger, J. M. (2005). Structure of the nuclease domain of ribonuclease III from M. tuberculosis at 2.1 A. Protein Sci. 14, 2744-2750. doi: $10.1110 /$ ps.051665905

Amarasinghe, A. K., Calin-Jageman, I., Harmouch, A., Sun, W., and Nicholson, A. W. (2001). Escherichia coli ribonuclease III: affinity purification of hexahistidine-tagged enzyme and assays for substrate binding and cleavage. Methods Enzymol. 342, 143-158. doi: 10.1016/S0076-6879(01)42542-0

Arraiano, C. M., Andrade, J. M., Domingues, S., Guinote, I. B., Malecki, M., Matos, R. G., et al. (2010). The critical role of RNA processing and degradation in the control of gene expression. FEMS Microbiol. Rev. 34, 883-923. doi: 10.1111/j. 1574-6976.2010.00242.x

Baumgardt, K., Charoenpanich, P., McIntosh, M., Schikora, A., Stein, E., Thalmann, S., et al. (2014). RNase E affects the expression of the acylhomoserine lactone synthase gene sinI in Sinorhizobium meliloti. J. Bacteriol. 196, 1435-1447. doi: 10.1128/JB.01471-13

Baumgardt, K., Melior, H., Madhugiri, R., Thalmann, S., Schikora, A., McIntosh, M., et al. (2017). RNase E and RNase J are needed for S-adenosylmethionine homeostasis in Sinorhizobium meliloti. Microbiology 163, 570-583. doi: 10.1099/mic.0.000442

Baumgardt, K., Smidova, K., Rahn, H., Lochnit, G., Robledo, M., and EvguenievaHackenberg, E. (2016). The stress-related, rhizobial small RNA RcsR1 destabilizes the autoinducer synthase encoding mRNA sinI in Sinorhizobium meliloti. RNA Biol. 13, 486-499. doi: 10.1080/15476286.2015.1110673

Beringer, J. E. (1974). R factor transfer in Rhizobium leguminosarum. J. Gen. Microbiol. 84, 188-198. doi: 10.1099/00221287-84-1-188

Blaszczyk, J., Gan, J., Tropea, J. E., Court, D. L., Waugh, D. S., and Ji, X. (2004). Noncatalytic assembly of ribonuclease III with double-stranded RNA. Structure 12, 457-466. doi: 10.1016/j.str.2004.02.004

Blaszczyk, J., Tropea, J. E., Bubunenko, M., Routzahn, K. M., Waugh, D. S., Court, D. L., et al. (2001). Crystallographic and modeling studies of RNase III suggest a mechanism for double-stranded RNA cleavage. Structure 9, 1225-1236. doi: 10.1016/S0969-2126(01)00685-2

Casse, F., Boucher, C., Julliot, J. S., Michel, M., and Dénarié, J. (1979). Identification and characterization of large plasmids in Rhizobium meliloti using agarose gel electrophoresis. J. Gen. Microbiol. 113, 229-242. doi: 10.1099/00221287113-2-229

Chelladurai, B., Li, H., Zhang, K., and Nicholson, A. W. (1993). Mutational analysis of a ribonuclease III processing signal. Biochemistry 32, 7549-7558. doi: 10.1021/bi00080a029

Chelladurai, B. S., Li, H., and Nicholson, A. W. (1991). A conserved sequence element in ribonuclease III processing signals is not required for accurate in vitro enzymatic cleavage. Nucleic Acids Res. 19, 1759-1766. doi: 10.1093/nar/ 19.8.1759

Dasgupta, S., Fernandez, L., Kameyama, L., Inada, T., Nakamura, Y., Pappas, A., et al. (1998). Genetic uncoupling of the dsRNA-binding and RNA cleavage activities of the Escherichia coli endoribonuclease RNase III-the effect of dsRNA binding on gene expression. Mol. Microbiol. 28, 629-640. doi: 10.1046/j.13652958.1998.00828.x

Davies, B. W., and Walker, G. C. (2007). Disruption of sitA compromises Sinorhizobium meliloti for manganese uptake required for protection against oxidative stress. J. Bacteriol. 189, 2101-2109. doi: 10.1128/JB.01377-06

Dereeper, A., Audic, S., Claverie, J. M., and Blanc, G. (2010). BLAST-EXPLORER helps you building datasets for phylogenetic analysis. BMC Evol. Biol. 10:8. doi: 10.1186/1471-2148-10-8

Dereeper, A., Guignon, V., Blanc, G., Audic, S., Buffet, S., Chevenet, F., et al. (2008). Phylogeny.fr: robust phylogenetic analysis for the non-specialist. Nucleic Acids Res. 36, W465-W469. doi: 10.1093/nar/gkn180

Dunn, J. J., and Studier, F. W. (1983). Complete nucleotide sequence of bacteriophage T7 DNA and the locations of T7 genetic elements. J. Mol. Biol. 166, 477-535. doi: 10.1016/S0022-2836(83)80282-4

Durand, S., Tomasini, A., Braun, F., Condon, C., and Romby, P. (2015). sRNA and mRNA turnover in Gram-positive bacteria. FEMS Microbiol. Rev. 39, 316-330. doi: 10.1093/femsre/fuv007

Evguenieva-Hackenberg, E., and Klug, G. (2000). RNase III processing of intervening sequences found in helix 9 of $23 \mathrm{~S}$ rRNA in the alpha subclass of
Proteobacteria. J. Bacteriol. 182, 4719-4729. doi: 10.1128/JB.182.17.4719-4729. 2000

Ferguson, B. J., Lin, M. H., and Gresshoff, P. M. (2013). Regulation of legume nodulation by acidic growth conditions. Plant Signal. Behav. 8:e23426. doi: $10.4161 /$ psb.23426

Fisher, R. F., and Long, S. R. (1992). Rhizobium-plant signal exchange. Nature 357, 655-660. doi: 10.1038/357655a0

Gross, G., and Dunn, J. J. (1987). Structure of secondary cleavage sites of E. coli RNAaseIII in A3t RNA from bacteriophage T7. Nucleic Acids Res. 15, 431-442. doi: 10.1093/nar/15.2.431

Haddad, N., Saramago, M., Matos, R. G., Prevost, H., and Arraiano, C. M. (2013). Characterization of the biochemical properties of Campylobacter jejuni RNase III. Biosci. Rep. 33:e00082. doi: 10.1042/BSR20130090

Hammond, S. M. (2005). Dicing and slicing: the core machinery of the RNA interference pathway. FEBS Lett. 579, 5822-5829. doi: 10.1016/j.febslet.2005. 08.079

Hood, G., Karunakaran, R., Downie, J. A., and Poole, P. (2015). MgtE from Rhizobium leguminosarum is a $\mathrm{Mg}^{2+}$ channel essential for growth at low $\mathrm{pH}$ and N2 fixation on specific plants. Mol. Plant-Microbe Interact. 28, 1281-1287. doi: 10.1094/MPMI-07-15-0166-R

Hood, G., Ramachandran, V., East, A. K., Downie, J. A., and Poole, P. S. (2017). Manganese transport is essential for $\mathrm{N} 2$-fixation by Rhizobium leguminosarum in bacteroids from galegoid but not phaseoloid nodules. Environ. Microbiol. 19, 2715-2726. doi: 10.1111/1462-2920.13773

Jacob, A. I., Kohrer, C., Davies, B. W., RajBhandary, U. L., and Walker, G. C. (2013). Conserved bacterial RNase YbeY plays key roles in 70S ribosome quality control and 16S rRNA maturation. Mol. Cell 49, 427-438. doi: 10.1016/j.molcel.2012. 11.025

Ji, X. (2006). Structural basis for non-catalytic and catalytic activities of ribonuclease III. Acta Crystallogr. Sect. D Biol. Crystallogr. 62, 933-940. doi: 10.1107/S090744490601153X

Khan, S. R., Gaines, J., Roop, R. M. II, and Farrand, S. K. (2008). Broad-host-range expression vectors with tightly regulated promoters and their use to examine the influence of TraR and TraM expression on Ti plasmid quorum sensing. Appl. Environ. Microbiol. 74, 5053-5062. doi: 10.1128/AEM.01098-08

Laalami, S., Zig, L., and Putzer, H. (2014). Initiation of mRNA decay in bacteria. Cell. Mol. Life Sci. CMLS 71, 1799-1828. doi: 10.1007/s00018-013-1472-4

Larkin, M. A., Blackshields, G., Brown, N. P., Chenna, R., McGettigan, P. A., McWilliam, H., et al. (2007). Clustal W and clustal X version 2.0. Bioinformatics 23, 2947-2948. doi: 10.1093/bioinformatics/btm404

Lasa, I., Toledo-Arana, A., Dobin, A., Villanueva, M., de los Mozos, I. R., Vergara-Irigaray, M., et al. (2011). Genome-wide antisense transcription drives mRNA processing in bacteria. Proc. Natl. Acad. Sci. U.S.A. 108, 20172-20177. doi: 10.1073/pnas.1113521108

Li, H., and Nicholson, A. W. (1996). Defining the enzyme binding domain of a ribonuclease III processing signal. Ethylation interference and hydroxyl radical footprinting using catalytically inactive RNase III mutants. EMBO J. 15, 1421-1433.

Madhugiri, R., and Evguenieva-Hackenberg, E. (2009). RNase J is involved in the $5^{\prime}$-end maturation of $16 \mathrm{~S}$ rRNA and $23 \mathrm{~S}$ rRNA in Sinorhizobium meliloti. FEBS Lett. 583, 2339-2342. doi: 10.1016/j.febslet.2009.06.026

Matos, R. G., Casinhas, J., Barria, C., Dos Santos, R. F., Silva, I. J., and Arraiano, C. M. (2017). The role of ribonucleases and sRNAs in the virulence of foodborne pathogens. Front. Microbiol. 8:910. doi: 10.3389/fmicb.2017.00910

Matsunaga, J., Simons, E. L., and Simons, R. W. (1996). RNase III autoregulation: structure and function of $\mathrm{rncO}$, the posttranscriptional "operator". RNA 2, 1228-1240.

Meng, W., and Nicholson, A. W. (2008). Heterodimer-based analysis of subunit and domain contributions to double-stranded RNA processing by Escherichia coli RNase III in vitro. Biochem. J. 410, 39-48. doi: 10.1042/BJ20071047

Milligan, J. F., Groebe, D. R., Witherell, G. W., and Uhlenbeck, O. C. (1987). Oligoribonucleotide synthesis using T7 RNA polymerase and synthetic DNA templates. Nucleic Acids Res. 15, 8783-8798. doi: 10.1093/nar/15.21.8783

Nicholson, A. W. (2014). Ribonuclease III mechanisms of double-stranded RNA cleavage. Wiley Interdiscipl. Rev. RNA 5, 31-48. doi: 10.1002/wrna.1195

Nicholson, A. W., Niebling, K. R., McOsker, P. L., and Robertson, H. D. (1988). Accurate in vitro cleavage by RNase III of phosphorothioate-substituted RNA 
processing signals in bacteriophage T7 early mRNA. Nucleic Acids Res. 16, 1577-1591. doi: 10.1093/nar/16.4.1577

Rigaud, J., and Puppo, A. (1975). Indole-3 acetic acid catabolism by soybean bacteroids. J. Gen. Microbiol. 88, 223-228. doi: 10.1099/00221287-88$2-223$

Robledo, M., Jiménez-Zurdo, J. I., and Becker, A. (2015). Antisense transcription of symbiotic genes in Sinorhizobium meliloti. Symbiosis 67, 55-67. doi: 10.1007/ s13199-015-0358-7

Saramago, M., Barria, C., Arraiano, C. M., and Domingues, S. (2015). Ribonucleases, antisense RNAs and the control of bacterial plasmids. Plasmid 78, 26-36. doi: 10.1016/j.plasmid.2014.09.003

Saramago, M., Barria, C., Dos Santos, R. F., Silva, I. J., Pobre, V., Domingues, S., et al. (2014a). The role of RNases in the regulation of small RNAs. Curr. Opin. Microbiol. 18, 105-115. doi: 10.1016/j.mib.2014.02.009

Saramago, M., Domingues, S., Viegas, S. C., and Arraiano, C. M. (2014b). Biofilm formation and antibiotic resistance in Salmonella typhimurium are affected by different ribonucleases. J. Microbiol. Biotechnol. 24, 8-12. doi: 10.4014/jmb. 1309.09046

Saramago, M., Peregrina, A., Robledo, M., Matos, R. G., Hilker, R., Serrania, J., et al. (2017). Sinorhizobium meliloti YbeY is an endoribonuclease with unprecedented catalytic features, acting as silencing enzyme in riboregulation. Nucleic Acids Res. 45, 1371-1391. doi: 10.1093/nar/gkw 1234

Schafer, A., Tauch, A., Jager, W., Kalinowski, J., Thierbach, G., and Puhler, A. (1994). Small mobilizable multi-purpose cloning vectors derived from the Escherichia coli plasmids pK18 and pK19: selection of defined deletions in the chromosome of Corynebacterium glutamicum. Gene 145, 69-73. doi: 10.1016/ 0378-1119(94)90324-7

Silva, I. J., Saramago, M., Dressaire, C., Domingues, S., Viegas, S. C., and Arraiano, C. M. (2011). Importance and key events of prokaryotic RNA decay: the ultimate fate of an RNA molecule. Wiley Interdiscipl. Rev. RNA 2, 818-836. doi: 10.1002/wrna.94

Simon, R., Priefer, U., and Puhler, A. (1983). A broad host range mobilization system for in vivo genetic engineering: transposon mutagenesis in gram negative bacteria. Nat. Biotechnol. 1, 784-791. doi: 10.1038/nbt1183-784
Soto, M. J., Dominguez-Ferreras, A., Perez-Mendoza, D., Sanjuan, J., and Olivares, J. (2009). Mutualism versus pathogenesis: the give-and-take in plantbacteria interactions. Cell. Microbiol. 11, 381-388. doi: 10.1111/j.1462-5822. 2009.01282.x

Sun, W., and Nicholson, A. W. (2001). Mechanism of action of Escherichia coli ribonuclease III. Stringent chemical requirement for the glutamic acid 117 side chain and $\mathrm{Mn}^{2+}$ rescue of the Glu117Asp mutant. Biochemistry 40, 5102-5110. doi: 10.1021/bi010022d

Sun, W., Pertzev, A., and Nicholson, A. W. (2005). Catalytic mechanism of Escherichia coli ribonuclease III: kinetic and inhibitor evidence for the involvement of two magnesium ions in RNA phosphodiester hydrolysis. Nucleic Acids Res. 33, 807-815. doi: 10.1093/nar/gki197

Viegas, S. C., Mil-Homens, D., Fialho, A. M., and Arraiano, C. M. (2013). The virulence of Salmonella enterica serovar typhimurium in the insect model galleria mellonella is impaired by mutations in RNase E and RNase III. Appl. Environ. Microbiol. 79, 6124-6133. doi: 10.1128/AEM.02044-13

Viegas, S. C., Silva, I. J., Saramago, M., Domingues, S., and Arraiano, C. M. (2011). Regulation of the small regulatory RNA MicA by ribonuclease III: a target-dependent pathway. Nucleic Acids Res. 39, 2918-2930. doi: 10.1093/nar/ gkq1239

Wu, C. X., Xu, X. J., Zheng, K., Liu, F., Yang, X. D., Chen, C. F., et al. (2016). Characterization of ribonuclease III from Brucella. Gene 579, 183-192. doi: 10.1016/j.gene.2015.12.068

Conflict of Interest Statement: The authors declare that the research was conducted in the absence of any commercial or financial relationships that could be construed as a potential conflict of interest.

Copyright (c) 2018 Saramago, Robledo, Matos, Jiménez-Zurdo and Arraiano. This is an open-access article distributed under the terms of the Creative Commons Attribution License (CC BY). The use, distribution or reproduction in other forums is permitted, provided the original author(s) and the copyright owner(s) are credited and that the original publication in this journal is cited, in accordance with accepted academic practice. No use, distribution or reproduction is permitted which does not comply with these terms. 